\title{
Optimizing group judgmental accuracy in the presence of interdependencies*
}

\author{
LLOYD SHAPLEY \\ Department of Economics, University of California at Los Angeles, CA 90024 \\ BERNARD GROFMAN \\ School of Social Sciences, University of California at Irvine, Irvine, CA 92717
}

\begin{abstract}
Consider a group of people confronted with a dichotomous choice (for example, a yes or no decision). Assume that we can characterize each person by a probability, $p_{i}$, of making the 'better' of the two choices open to the group, such that we define 'better' in terms of some linear ordering of the alternatives. If individual choices are independent, and if the a priori likelihood that either of the two choices is correct is one half, we show that the group decision procedure that maximizes the likelihood that the group will make the better of the two choices open to it is a weighted voting rule that assigns weights, $w_{i}$, such that$$
w_{i} \propto \log \frac{p_{i}}{1-p_{i}}
$$

We then examine the implications for optimial group choice of interdependencies among individual choices.
\end{abstract}

\section{Introduction}

The literature on social choice rooted in welfare economics, whose seminal work is Kenneth Arrow's Social Choice and Individual Values (1962), has focused on the problems of preference aggregation. The central question of this literature can be stated loosely as 'Is there a way of combining individual preferences so as to result in a social ordering that satisfies certain "reasonable" properties, for example, nondictatorship, positive-responsiveness, and so forth?' Clearly, this and similar questions addressed in the social choice literature (see Plott, 1976, for an excellent and comprehensive

* This research was supported by NSF Grant \# SES 80-07915. We acknowledge the assistance of Professor Thomas Cover, Department of Statistics, Stanford University, in identifying references to earlier results related to the key theorem in this paper; the assistance of the staff of the Word Processing Center of the School of Social Sciences, University of California, Ir vine, and of Sue Pursche and Laurel Eaton for typing, editing, and bibliographic search for this manuscript; and the helpful suggestions of three anonymous referees. 
review) are of considerable importance to democratic theory. In the post WWII focus on questions of preference aggregation, however, other issues of at least equal importance to democratic theory have been lost sight of. ${ }^{1}$ In this essay we examine one such issue, the accuracy of group decision making. ${ }^{2}$

The Condorcet-Poisson approach is based on a notion of probabilistic choice. Consider a group of $N$ voters (for simplicity assume $N$ odd) confronting a dichotomous choice (for example, a YES or NO decision) in which the $i$ th voter can be characterized by a probability, $p_{i}$, of making the 'better' of the two choices available to the group, such that 'better' is defined in terms of some linear ordering of the alternatives. This probability represents the 'competence' of the $i$ th voter on choices of this kind. A natural question to ask is 'How likely is the group to make the correct decision (that is, to pick the better of the two alternatives)?'

A potential objection even to considering such a question is that the notion of 'competence' is not well defined and may be impossible to operationalize. We have three responses.

First, even in situations in which there may not be a 'correct' choice, the notion of the expected choice that would be made by an infinitely large voting population under a majority voting procedure can be made precise, and this can be taken to be the 'correct' choice. Here, correctness is defined in terms of an accurate representation of what would be the majority sentiment. ${ }^{3}$

Second, in many situations (for example, in the taking of standardized multiple-choice exams, or in predicting whether gold will go up or down in the next day's trading), in principle, we can precisely define competence and assess a person's over-time 'track record' for predictive accuracy.

Third, even if a record of predictive success is unavailable, other voter experts can subjectively evaluate the relative competence of each voter (expert), and we can combine these evaluations in a convergent iterative procedure (described in Berge, 1975, and Mirkin, 1979: Ch. 4), which generates an aggregated estimate of the perceived relative competence of each participant in the decision process, which we can use to assign $p_{i}$ values. ${ }^{4}$

The classic theorem about group competence is due to Condorcet and has come to be known as the Condorcet Jury Theorem.

\section{Theorem I: Condorcet Jury Theory (1785)}

If voters are homogenous (that is, $p_{i}=p=\bar{p}$ for all $i$ ), and $N$ voters make independent decisions and the group decision rule is simple majority, and if we let $m=\frac{N+1}{2}$, and if we assume that the a priori odds are even as 
to which of the two alternatives being chosen is the better; if we denote the probability that the group will make the correct choice as $P_{N}$, then if $1>p>\frac{1}{2}$ then $P_{N}$ is monotonically increasing in $N$ and $\lim _{N \rightarrow \infty} P_{N} \rightarrow 1$; if $0<p<\frac{1}{2}$ then $P_{N}$ is monotonically decreasing in $N$ and $\lim _{N \rightarrow \infty} P_{N} \rightarrow 0$; while if $p=\frac{1}{2}$ then $P_{N}=\frac{1}{2}$ for all $N$. Also,

$$
P_{N}=\sum_{h=m}^{N}\left(\begin{array}{l}
N \\
h
\end{array}\right) p^{h}(1-p)^{N-h}
$$

In other words, if $p>\frac{1}{2}\left(p<\frac{1}{2}\right)$, then the larger the number of voters the more (less) likely is the group to make the correct decision, and that probability approaches one zero as the number of voters expands. ${ }^{5}$

The Condorcet Jury Theorem in this original form incorporates the highly unrealistic assumption of voter homogeneity. But, that assumption is not crucial. It is trivial to show that if competence $\left(p_{i}\right)$ is normally distributed (or for any distribution that is symmetric around its mean), we need merely replace $p$ with $\bar{p}$ in Equation (1) and in the expressions previous to it. ${ }^{6}$

\section{The Bayesian optimal group decision rule}

Virtually all of the research in the Condorcet-Poisson tradition reviewed in Section I concerns decisions in a 'one-person, one-vote' context in which each person's views receive equal weight in the final group decision (Grofman and Owen, 1984 forthcoming). A natural question, and one that this essay examines is: 'Given a group of persons of unequal judgmental competence, what is the best mechanism for pooling their judgments into a collective choice; that is, how can we maximize the likely judgmental accuracy of the group decision?' In general, we would not expect that the desired mechanism would be a decision procedure that weights all voters equally regardless of their competence. Consider a group with competences $(.9, .9, .6, .6$, .6), whose choices are independently made. If we let a member of maximum competence decide, $P_{N}=.900$; if we let the group decide by majority rule, $P_{N}=.877$; but, if we let the group decide under a 'weighted' majority voting 7 rule with weights $(1 / 3,1 / 3,1 / 9,1 / 9,1 / 9)$, then $P_{N}=.927$. (We continue to use $\boldsymbol{P}_{N}$ to denote the probability that the group reaches the correct majority judgment. It will be clear from the context whether we are refer- 
ring to a simple majority or a weighted majority.) This result may at first appear to be a rather counterintuitive finding, since the best of the three rules is one in which the addition of voters with only .6 competence can be used to increase the group competence above that of its most competent (.9) members and above that of the simple equal weights case. This result is easier to accept if we note that these weights are equivalent to letting the two 'wisest' members of the group rule if they agree with each other, but if they disagree, we let the others 'break the tie' by a majority vote among the three of them.

If, for another example, we examine a three-member group with competences $(.55, .60, .70)$, whose choices are independently made, then we may show (by enumerating all possible options, which are few in number) that an optimal voting rule is to assign weights $(0,0,1)$, that is, to give the most competent voter dictatorial powers. On the other hand, if the competence of the first member (.55) is adjusted upward so that we have $p_{i}$ values of $(.65, .60, .70)$, then we may show that the optimal voting rule is simple majority, that is, weights $(1,1,1)$. Thus, improving the competence of one voter appears dramatically to affect the optimal allocation of weights to all the voters in the group. We shall see that this appearance is somewhat misleading.

We may motivate the logic underlying these two examples with the following theorem:

\section{Theorem II: (The Bayesian Optimal Decision Rule)}

In a heterogeneous group, in which individual choices are mutually independent, and the a priori likelihood that either of the two choices open to the group is correct is one half, the decision rule that maximizes $P_{N}$ is a majority weighted voting rule, obtained by assigning weights, $w_{i}$ :

$$
w_{i} \propto \log \frac{p_{i}}{1-p_{i}} .
$$

Proof: Shapley (1979): see Nitzan and Paroush (1982) ${ }^{8}$

In this theorem we assume that the options to the group are a priori equally likely. If one alternative were more likely to be correct than another or if we were to regard one alternative as somehow a priori more desirable than another (if we were disinclined, say, toward frequent constitutional amendments), then we would wish to require a special (weighted) majority for passage. ${ }^{9}$ Individual weights, however, would still be based on the voter's $\log$-likelihood ratio.

It is important to note that once we pick a logarithmic base, the weight 
assignment we give to a person to optimize group judgmental accuracy is purely a function of that person's competence and is independent of the competence of the other members of the group or of group size. This result is quite counterintuitive. Of course, while a person's weight may stay constant, his power ${ }^{10}$ to influence decision outcomes will vary as a function of the weights of the other members of the group. In some groups a person may be dictatorial. In others he may be, in the language of game theory, a dummy, that is, he may have no ability to influence outcomes. A strong feature of the theorem is that the optimality of the group decision process is guaranteed once we make the proper individual weight assignments.

To return to our earlier examples (using logs to the base $e$ ), we have

$$
\begin{aligned}
& \ln \frac{.55}{.45}=.0872 \\
& \ln \frac{.60}{.40}=.1761 \\
& \ln \frac{.65}{.35}=.2689 \\
& \ln \frac{.70}{.30}=.3680 \\
& \ln \frac{.90}{.10}=.9542
\end{aligned}
$$

In the case of the five-member group with competences $(.9, .9, .6, .6)$ the optimum weight assignment by Theorem II, is $(.9542, .9542, .1761, .1761$, $.1761)$, which we can normalize to $(.392, .392, .072, .072, .072)$.

However, optimal weight assignments, even when normalized, are almost never unique, and this example is no exception. Indeed, any set of positive numbers that satisfies the constraints

$$
\begin{aligned}
& w_{1}+w_{2}>w_{3}+w_{4}+w_{5} \\
& w_{1}+w_{3}+w_{4}>w_{2}+w_{5} \\
& w_{1}+w_{3}+w_{5}>w_{2}+w_{4} \\
& w_{1}+w_{4}+w_{5}>w_{2}+w_{3} \\
& w_{2}+w_{3}+w_{4}>w_{1}+w_{5} \\
& w_{2}+w_{2}+w_{5}>w_{1}+w_{4} \\
& w_{2}+w_{4}+w_{5}>w_{1}+w_{3}
\end{aligned}
$$

will also serve as a system of weights and maximize $P_{N}$ for this particular example. The assignment $(1 / 3,1 / 3,1 / 9,1 / 9,1 / 9)$, previously given, satisfies the expressions given in (7), as do such disparate other assignments as (.26, $.26, .16, .16, .16)$ and $(.47, .47, .02, .02, .02)$ and $(.32, .20, .18, .16, .15)$. The 
point is that all of these systems of weights define exactly the same 'winning coalitions' (Shapley, 1962). The same sets of voters have a majority of the weighted vote, no matter which of these weight assignments we use.

In the case of the three-member group with competences $(.55, .60, .70)$, the optimum weight by Theorem II is $(.0872, .1761, .3680)$, which we can normalize to obtain weight assignments of $(.138, .279, .583)$. It is clear that under this assignment $w_{3}>w_{1}+w_{2}$, and indeed, any assignment that satisfies this inequality (that is, which.makes member 3 a dictator) will also maximize $P_{N}$ just as well. If we upgrade the first member's competence to .65 , the optimum weight assignment becomes $(.2689, .1761, .3680)$, which, when normalized, becomes $(.329, .217, .453)$. Again, this assignment is not unique. Any weight assignment that satisfies the constraints that

$$
0 \leq w_{1}<\frac{w_{1}+w_{2}+w_{3}}{2}, i=1,2,3
$$

will serve to optimize $P_{N}$. It is not even necessary to insist that $w_{3}$ be the largest weight, despite the superior competence of member 3 . It is apparent that the conditions given in Equation (8) will be satisfied, for example, by simple majority rule, as we assert previously.

While for any particular example, the optimal weight assignments may vary considerably within some set of constraints such as that given in (8), however, the only weighting scheme that is optimal in all cases is the one given in equation (2). ${ }^{11}$ In particular we can assign the logarithmic weights in Equation (2) to each person separately and once and for all, independently of the number of other persons with whom that person may be grouped, or their competences. Up to a constant scaling factor, moreover, the weights in Equation (2) are unique in respect of this property.

\section{Interdependent competences}

Thus far we have assumed that each voter's choices are statistically independent of those of his or her fellows. This assumption implies, for example, that the probability that $i$ is correct given that $j$ is correct is the same as the probability that $i$ is correct given that $j$ is incorrect. We now consider some examples of what can happen if we relax this assumption. Our principal finding is that under certain circumstances nonmonotonic rules may be superior to monotonic ones. ${ }^{12}$

Example 1: Let us assume that we have a set of three voters, $\{1,2,3\}$, whose judgments with respect to some particular situation are such that one of them will surely be wrong while each of the others, independently, will be right with some fairly high probability, $r$, say, $r>\sqrt{2} / 2=.7071$. 
We do not know, however which voter is which. Each voter has probability $1 / 3$ of being the 'surely wrong' one. ${ }^{13}$

For this interdependent case, the unconditional probability of any given voter being correct is $\bar{p}=2 r / 3$. The conditional probability that, say, 1 is right given that 2 is right, however, is only $r / 2$, which is less than $\bar{p}$, whereas 1's probability of being right if 2 is wrong is greater than $\bar{p}$. Thus $\operatorname{Pr}\left(x_{i}\right.$ right $\mid x_{j}$ right $)<\operatorname{Pr}\left(x_{i}\right.$ right $\mid x_{j}$ wrong $)$ : their competences are negatively dependent (correlated). It is easy to calculate that the probability $p(k)$ that exactly $k$ voters are right is thus (see Table 1 ):

Table 1 .

\begin{tabular}{ll}
\hline$k$ & $p(k)$ \\
\hline 0 & $(1-r)^{2}$ \\
1 & $2 r(1-r)$ \\
2 & $r^{2}$ \\
3 & 0 \\
\hline
\end{tabular}

The unusual thing about these probabilities is that it is not true that the greater the size of the plurality in favor of an alternative, the more likely it is to be correct. Indeed, if the group is unanimous, it must be wrong! Of course, nothing like this could happen if the individual judgments were independent (assuming $p_{i}>1 / 2$, for all $i$ ).

Any statistical distribution that is fully symmetric in the voters, whether the probabilities are independent or not, comes down in the end to the consideration of a table of values of $p(k)$, like the previous one.

Theorem III: For such a symmetric distribution, weighted voting is optimal if and only if

$$
p(k)>p(N-k), \text { for all } k>N / 2 \text {. }
$$

Proof: In general, the probability that a choice is correct if there is a plurality of $\ell$ votes in its favor is given by

$$
\alpha_{\ell}=\frac{p(k)}{p(k)+p(N-k)}, \text { such that } \ell=2 k-N>0 .
$$

The desired result follows straightforwardly, given the monotonicity of any weighted voting rule (see Shapley, 1962).

In the preceding example $N$ is 3 and $\ell$ is 1 or 3 , so we have 


$$
\alpha_{1}=r /(2-r) \text { and } \alpha_{3}=0 .
$$

These values, although extreme, serve to illustrate that in cases exhibiting some negative correlation among individual judgments, a nonmonotonic decision rule may yield better results than simple majority voting or, indeed, than any weighted-majority rule. ${ }^{14}$ Using Table 1 , we find that the probability that majority voting will give the correct answer is

$$
p(2)+p(3)=r^{2} .
$$

But, the nonmonotonic rule that obeys the majority in a $(2,1)$ split decision but opposes the majority on a $(3,0)$ vote will give the correct answer with probability

$$
p(2)+p(0)=r^{2}+(1-r)^{2},
$$

which is distinctly larger than $r^{2}$.

\section{Example 2}

Now let there be 9 voters divided into 3 'districts' of 3 each, with the members of each district intercorrelated exactly as in example 1 (all with the same parameter $r$ ). But, the voting in each district is independent of the voting in each other district. As in example 1, the unconditioned individual probability of being correct is $\bar{p}=2 r / 3$. We shall show in this example that, for certain values of $r$, the best monotonic rule is of a compound form, yielding a higher likelihood of a correct choice than any decision rule representable by weighted voting.

Generalizing our previous approach, let $p(k, \ell, m)$ denote the probability that exactly $k$ of the first district, $\ell$ of the second, and $m$ of the third are correct in their judgment. Note that the probability that any of $k, \ell, m$ is 3 is zero. The relevant nonzero values of $p(k, \ell, m)$ are thus:

Table 2.

\begin{tabular}{llll}
\hline$k$ & $l$ & $m$ & $p(k, l, m)$ \\
\hline 2 & 2 & 2 & $r^{6}$ \\
2 & 2 & 1 & $2 r^{5}(1-r)$ \\
2 & 1 & 2 & $"$, \\
1 & 2 & 2 & $"$, \\
2 & 2 & 0 & $r^{4}(1-r)^{2}$ \\
2 & 0 & 2 & $"$, \\
0 & 2 & 2 & $"$ \\
\hline
\end{tabular}

Consider first simple majority voting. If we add the preceding entries for which $k+\ell+m \geq 5$, we find 


$$
P_{M}=r^{5}(6-5 r)
$$

(or, numerically: for $\bar{p}=.6 P_{M}=.886$, for $\bar{p}=.5 P_{M}=.534$ ). Surprisingly, unequal weights can sometimes do better than this, despite the symmetry of the situation. Take the weight vector $W=(1,1,1,0,0,0,0,0,0)$, for example. From example 1, we obtain

$$
P_{W}=r^{2}
$$

(or, numerically: for $p=.6 P_{M}=.810$, for $\bar{p}=.5 P=.562$ ), which is better than simple majority rule in the narrow range $.5<\bar{p}<.5216$. Strange! Three heads are better than nine!

But, a uniformly better rule is to vote by districts. Use majority rule in each district, then follow the advice of the majority of districts. We find the probability of a correct result by adding all the entries in the preceding table. The result is:

$$
P_{C}=r^{4}\left(3-2 r^{2}\right)
$$

(or, numerically: for $\bar{p}=.6 P=.905$ for $\bar{p}=.5 P=.594$ ). This is greater than $P_{W}$ for all values of $r$ less than 1 .

If we do not restrict ourselves to monotonic decision rules, then we can do still better by this rule: 'In each district choose the majority-preferred alternative if $\bar{\ell}=1$, but choose the unpreferred alternative if $\bar{\ell}=3$, then use a majority vote among the three districts.' The resulting probability of a correct decision is .718 if $\bar{p}=.5$ and .914 if $\bar{p}=.6 .^{15}$

\section{Discussion}

The theorems discussed in this essay concern dichotomous choice, but this restriction may not be as serious as it might at first seem. If a group must choose from a set of alternatives $(k \geq 2)$, then it may do so by using any one of a number of different binary choice procedures that decompose into sequences of pairwise (right fork or left fork) choices. The most common legislative procedure, the standard amendment procedure (see Farquharson, 1969; Roberts, 1973; and Miller, 1977), is a sequential binary choice process that pairs alternatives against one another, with the winner advancing into the next round. Other important voting procedures, for example, the Borda rule (Borda, 1781; Black, 1958; and Young, 1974), may also be represented in terms of the aggregation of information based entirely on pairwise choices. We can expect the choice of procedure to influence the likelihood of a correct choice, however. ${ }^{16}$ 
Interdependencies among voter choices may also be analyzed. In considering interdependent choices, it may be possible to partition the set of voters into discrete blocs, such that within each bloc choices may be correlated but there will be independence across blocs. For this partitioned set, for each bloc we can then find the optimal voting rule and assess the judgmental competence of the bloc, treating it as an entity that will be using the (internally) optimal rule for its decision making. Then, we simply apply Theorem II to the blocs to find the optimal bloc weights. Even if interbloc correlations exist, as long as they are small, partitioning the voters into discrete cluster-blocs and then proceeding as outlined will yield a very good approximation to optimality. (cf. Owen, 1983)

While the results of this essay seem particularly appropriate to analysis of the problem of 'information pooling,' in which the task is to weigh the advice of 'experts' or to reconcile 'expert' and 'nonexpert' conflicting opinion; we believe Theorem II to be of considerable general importance for democratic theory. Together with Theorem I (and related results), Theorem II sheds new light on a very old question: the merits of democracy as compared to that of rule by the elite. ${ }^{18}$ Theorem II shows us how to optimize the judgmental accuracy of group decision making. In this optimizing procedure the more competent will always be assigned at least as much weight as those less competent than themselves. But, especially for large $N$, simple majority rule may turn out to be 'near' optimal, and in most cases (as long as $p_{i}>.5$ ) even the less competent will receive some weight in the final decision.

\section{NOTES}

1. In the recent words of one scholar:

The exaggerated importance ascribed to Arrow's impossibility theorem suggests the fantasy that if only the theorem had some logical flaw, if only this cosmic joke were not planted in the process of aggregating preferences, then perhaps we could all have our way, and find and save our democratic soul. Then we could achieve economic and social justice without explicitly concerning ourselves with justice .... It is as though ... if only we could find the proper set of instrumental institutions and decision-rules, then we might never have to ask ourselves what kind of society we want (Thom, 1979: 194-195).

2. Our work is in the spirit of that done by pioneering scholars such as Condorcet (1785) and Poisson (1837), whose research on the accuracy of group decision-making has only recently been rediscovered. (See Gelfand and Solomon, 1973; Gillispie, 1972; Black, 1958; Grainger, 1956; Barry, 1969; Baker, 1967, 1975; Grofman, 1975. See also recent extensions by Gelfand and Solomon, 1974, 1975, 1977; Grofman, 1978, 1979, 1980a; Klevorick and Rothschild, 1978; Nagel and Neef, 1975; Grofman, Owen and Feld, 1982; Grofman, Feld and Owen, 1984 forthcoming; Grofman and Owen, 1984 forthcoming; Nitzan and Paroush, 1982; Miller, 1980; and Pinkham and Urken, 1981).

3. This approach has been suggested by Gelfand and Solomon (1977) and Grofman (1975, 
1980b). It harkens back to the Keynes (1936) 'beauty contest problem,' in which the task is to pick the winner of a beauty contest based on expectations of how other people will judge beauty (See Grofman, 1981).

4. We emphasize, however, that the models that we propose are not meant to apply in cases in which divergent preferences make agreement impossible, even in principle, on the criteria of choice. Nonetheless, many seeming disagreements about ends are actually disagreements about the probable consequences of particular courses of action. In particular, there may well exist a shared criterion on which to make evaluations, but disagreement as to how to apply that criterion to particular cases.

5. Convergence to asymptote is rapid, especially initially (for details, see Grofman, Feld and Owen, 1984 forthcoming). Hence, groups operating under simple majority rule are often considerably better (or considerably worse) in their judgmental accuracy compared to the decisions of their 'average' member. For example, if $p=.6$, then $p_{3}=.648, p_{7}=.710$, and $p_{13}=.753$; while if $p=.8$, then $p_{3}=.896, p_{7}=.967$ and $p_{13}=.993$. For large $N$, if $p>1 / 2$, then 'vox populi, vox dei'; that is, the group decision approaches infallibility.

6. See Grofman, 1978, 1979; Owen, Grofman and Feld, 1981; and Grofman, Owen and Feld, 1983. The Condorcet Jury Theorem can be extended in other ways, for example, by looking at the judgmental accuracy of supramajoritarian decision procedures (for example, $2 / 3$ unanimity), as a function of group size, and/or by introducing a discussion between Type I and Type II errors (for example, between 'convicting the innocent' and 'freeing the guilty'). These directions have been pursued by several authors. (See, for example, Feinberg, 1971; Walbert, 1971; Gelfand and Solomon, 1973, 1974, 1975, 1977; Nagel and Neef, 1975; Klevorick and Rothschild, 1978; and Grofman, 1979; 1980a. For detailed reviews of much of this work, see Penrod and Hastie, 1979; Grofman, 1980b. Related work includes Badger, 1972; Curtis, 1972; Schofield, 1971, 1972; and Niemi and Weisberg, 1972.)

7. In a weighted voting rule, players are assigned weights $w_{i}$. Without loss of generality we may normalize these weights so that $\Sigma w_{i}=1$. For passage of a motion, some specified proportion of the total weighted vote is required. In a majority weighted voting rule, a majority of the weighted votes is required for passage. See Riker and Shapley (1968) or Lucas (1974) for more detailed discussions of weighted voting and its properties. Weighted voting is used in the U.S. Electoral College, in the United Nations Security Council, in the International Monetary Fund, in certain bodies of the E.E.C., in some of the New York county legislatures, and in the conventions of many trade unions and other chapter or affiliate-based voluntary organizations. (See, for example, Brams, 1975; Owen, 1975; Dreyer and Schotter, 1978; Fischer and Schotter, forthcoming; Grofman and Scarrow, 1979; and Schotter, 1979.)

8. After this theorem was proved by the senior author, we learned that the mathematical content of the result was known, but in contexts completely removed from problems in group decision making, for example, as a theorem in pattern recognition and as a theorem in automata theory. (See Pierce, 1961; Minsky and Papert, 1969: Ch. 12.4; and Duda and Hart, 1973.) The result was also independently discovered by two economists (Nitzan and Paroush, 1980a, 1982). Since our proof of the theorem is similar to those already published, we have omitted it.

9. Implicitly we are weighting Type I and Type II error equally. See Nitzan and Paroush, 1984; references in Note 6 above; and Buchanan and Tullock, 1962.

10. By power, we refer to game-theoretic measures of voter decisiveness, for example, the Shapley-Shubik index or the Banzhaf index (see Shapley and Shubik, 1954; Banzhaf, 1966; Lucas, 1974; Brams, 1975; Straffin, 1978; Schotter, 1979; Dubey and Shapley, 1979; and Nevison, 1979). 
11. We might note that the seemingly abrupt change in optimal weight assignments as the first member's competence is raised from .55 to .65 loses some of its significance when we realize that the weights in Equation (2) derived from the likelihood that ratios act in a continuous fashion if the competences are varied. There is, indeed, an abrupt change in the nature of the optimum voting rule, because there are only a small finite number of possible 'winning coalitions,' but this abruptness does not have to be reflected in the way that the optimal weights act.

12. A decision rule is called 'monotonic' if the decision would not be changed when an opposing vote is switched to a vote favoring the decision.

13. How could this peculiar situation come about? Perhaps there is a malicious opponent, desirous of promoting the 'wrong' decision, who has just enough resources to deceive one voter or to buy him off, or whatever. The story here does not really matter, however, as we are using the example principally to illustrate certain mathematical properties.

14. If smaller values of $r$ are considered, a curious anomaly can appear. Thus, if $r$ is less than $2 / 3$, then $r^{2}$ is less than the unconditioned probability $\bar{p}=2 r / 3$, which means that majority rule is now inferior to making one of the voters a dictator. So, if we are restricted to weighted-voting rules, the asymmetrical weights $(3,1,1)$ will work better than the symmetric weights $(1,1,1)$. Of course, since $\bar{p}$ in this case is less than $1 / 2$, one would be still better off making the decision by chance!

15. This is an example of a 'compound simple game,' denoted in game theory by the symbol $M 3\{M 3, M 3, M 3\}$; we cannot represent it by a single system of weighted votes. The game theory symbols for the other two rules mentioned in this example are $M 9$ (simple majority rule) and $M 3+O 6$ (majority rule by three members, plus six 'dummies'). See Shapley (1962).

16. Extending the result to the continuous case to compute point prediction or internal estimation, we believe, is also straightforward. The foundations for such an extension already exist in the literature on Bayesian decision theory. (See, for example, Bordley, 1980; and Mirkin, 1979: Chapter 4.)

17. Grofman, Owen, and Feld (1982a) show that the $\log \frac{p_{i}}{1-p_{i}}$ values, given not unreasonable assumptions, can be very well approximated by looking at the proportion of times in which voter $i$ agrees with the (unweighted) group majority. (See also Mirkin, 1979: 173.) Nicholas Miller (unpublished research) has used this technique to construct a hypothetical 'test-taker' for multiple choice exams based on the plurality choice among a set of actual exam-takers. The performance of this hypothetical test-taker is well above the mean score of those actually taking the exam.

\section{REFERENCES}

Arrow, K. (1962). Social choice and individual values. New York: Wiley.

Badger, W. (1972). Political individualism, positional preferences, and optimal decision rules. Probability models of collective decision-making. In R. Niemi and H. Weisberg (Eds.), Columbus, Ohio: Merrill.

Baker, K.M. (1975). Condorcet: From natural philosophy to social mathematics. Chicago: University of Chicago Press.

Baker, K.M. (1967). Scientism, elitism, and liberalism: The case of Condorcet. Studies in Voltaire and the Eighteenth Century 55: 129-156.

Banzhaf, J.F. III. (1966). Multi-member electoral districts - Do they violate the 'one-manone-vote' principle? Yale Law Journal 75: 1309-1388. 
Barry, B. (1969). The public interest. Proceedings of the Aristotelian Society, Supplementary Volume 38: 1-18.

Berge, C. (1975). Introduction à la theorie des hypergraphes. Montreal: Montreal University Press.

Black, D. (1958). The theory of committees and elections. London: Cambridge University Press.

Borda, J.C. (1781). Memoire sur les Elections au Scrutin. Histoire de l'Academie Royale des Sciences. Translated with commentary, de Grazia, 1953.

Bordley, R.F. (1980). Aggregating individual probability assessments. Research publication, General Motors Research Laboratories, 30 May 1980, No. GMR-3321.

Brams, S.J. (1975). Game theory and politics. New York: Free Press.

Buchanan, J., and Tullock, G. (1962). The calculus of consent. Ann Arbor: University of Michigan Press.

Condorcet, N.C. de (1785). Essai sur l'application de l'analyse à la probabilité des decisions rendues à la pluralité des voix. Paris.

Curtis, R. (1972). Decision rules and collective values in constitutional choice. In R. Niemi and $\mathbf{H}$. Weisberg (Eds.), Probability models of collective decision making. Columbus, Ohio: Merrill.

Davis, J.H. (1973). Group decision and social interaction: A theory of social decision schemes. Psychological Review 80 (2) (March): 97-125.

Dreyer, J., and Schotter, A. (1978). Power relationships in the international monetary fund: The consequences of quota changes. Unpublished Manuscript.

Dubey, P., and Shapley, L.S. (1979). Mathematical properties of the Banzhaf power index. Mathematics of Operations Research 4 (2) (May): 99-131.

Duda, R.O., and Hart, P.E. (1973). Pattern classification and scene analysis. New York: Wiley.

Farquharson, R. (1969). Theory of voting. New Haven, Conn.: Yale University Press.

Feinberg, W.E. (1971). Teaching type I and type II errors: The judicial process. The American Statistician, June: 30-32.

Fischer, D., and Schotter, A. The paradox of redistribution in the allocation of voting weights. Public Choice. Forthcoming.

Gelfand, A., and Solomon, H. (1973). A study of Poisson's models for jury verdicts in criminal and civil trials. Journal of American Statistical Association 68 (June): 271-278.

Gelfand, A., and Solomon, H. (1974). Modelling jury verdicts in the American legal system. Journal of American Statistical Association 69 (March): 32-37.

Gelfand, A., and Solomon, H. (1975). Analyzing the decision-making process of the American jury. Journal of the American Statistical Association 70 (June): 305-310.

Gelfand, A., and Solomon, H. (1977). Comparing juries: An argument in favor of twelvemember juries. Jurimetrics 17: 292-313.

Gelfand, A., and Solomon, H. (1977). An argument in favor of twelve-member juries. In S. Nagel (Ed.), Modelling the Criminal Justice System, Sage Criminal Justice System Annual 7: 205-220. Beverly Hills, Calif.: Sage Publications.

Gillespie, C.C. (1972). Probability and politics: LaPlace, Condorcet, and Turgot. Proceedings of the American Philosophical Society 116 (1) (Feb.): 1-20.

Grainger, G.G. de (1956). La mathematique sociale du Marquis de Condorcet. Paris: Presses Universitaires de France.

Grofman, B. (1975). Mathematics and politics: Mathematical reasoning and optimal jury decision processes. Plus, Reply. In M. Black (Ed.), Problems of choice and decision: Proceedings of a colloquium held in Aspen Colorado, June 24-July 6, 1974, 331-337; 544-547. Cornell University Program on Science, Technology and Society and Aspen Institute for Humanistic Studies: Photo-offset. 
Grofman, B. (1975). A comment on democratic theory: A preliminary mathematical model. Public Choice 21 (Spring): 100-103.

Grofman, B. (1978). Judgmental competence of individuals and groups in a dichotomous choice situation. Journal of Mathematical Sociology 6 (1): 47-60.

Grofman, B. (1979). The case for majority jury verdicts. Trial Magazine, December: 23-25, $29,47-48$.

Grofman, B. (1980a). Preliminary models of jury decision-making. In G. Tullock (Ed.), Frontiers of Economics 3. Blacksburg, Va.: Center for Study of Public Choice, Virginia Polytechnic Institute and State University.

Grofman, B. (1980b). Mathematical modeling of jury/juror decision making. In B.D. Sales (Ed.), Perspectives in law and psychology, Volume II: The jury judicial and trial processes, 305-351. Plenum.

Grofman, B. (1981). Predicting the outcomes of a Keynesian beauty context. Unpublished manuscript.

Grofman, B., and Owen, G. (Eds.), Information pooling and group decision making. Westport, Conn.: JAI Press. 1984 forthcoming.

Grofman, B., and Owen, G. (1983). Thirteen theorems in search of the truth. Theory and Decision 15: 261-278.

Grofman, B., Owen, G., and Feld, L. (1982). Average competence, variability in competence, and the accuracy of statistically pooled group decision making. Psychological Reports 50: 683-688.

Grofman, B., and Scarrow, H. (1979). Game theory and the U.S. Courts. In S. Brams, G. Schwödiauer and A. Schotter (Eds.), Applied game theory. Vienna: Springer-Verlag.

Grofman, B., Feld, S., and Owen, G. Group size and the performance of a composite group majority on multiple item decision tasks. Organizational behavior and human performance. 1984 forthcoming.

Keynes, J.M. (1936). General theory of employment, interest, and money. New York: Harcourt, Brace, and World.

Klevorick, A.K., and Rothschild, M. (1978). The jury decision process. Grant proposal to the National Science Foundation.

Klevorick, A.K., and Rothschild, M. (1979). A model of the jury decision process. Journal of Legal Studies, January: 141-164.

Lucas, W.F. (1974). Measuring power in weighted voting systems. In Case studies in applied mathematics, 42-106. Mathematics Association of America.

Luce, R.D. (1959). Individual choice behavior. New York: Wiley.

Margolis, H. (1976). A note on incompetence. Public Choice 26: 119-129.

Miller, N.R. (1977). Graph-theoretical approaches to the theory of voting. American Journal of Political Science 21 (November).

Miller, N.R. (1980). A new solution set for tournaments and majority voting. American Journal of Political Science 24.

Minsky, M., and Papert, S. (1969), Perceptrons: An introduction to computational geometry. Cambridge: MIT Press.

Mirkin, B. (1979). Group choice. New York: Halsted Press.

Moore, E.E., and Shannon, C.E. (1956a). Reliable circuits using less reliable relays, I. Franklin Institute, Philadelphia Journal 262: 191-208.

Moore, E.E., and Shannon, C.E. (1956b). Reliable circuits using less reliable relays, II. Franklin Institute, Philadelphia Journal 262: 281-297.

Nagel, S.S., and Neef, M. (1975). Deductive modeling to determine an optimum jury size and fraction required to convict. Washington University Law Review, 933-978.

Nevison, C.H. (1979). Structural power and satisfaction in simple games. In S. Brams, G. Schwödiauer and A. Schotter (Eds.), Applied game theory. Vienna: Springer-Verlag. 
Niemi, R., and Weisberg, H. (1972). The effects of group size on collective decision making. In Probability models of collective decision-making. Columbus, Ohio: Merrill.

Nitzan, S., and Paroush, J. (1980a). Discussion Paper \# 8017. Bar-Ilan University, Israel.

Nitzan, S., and Paroush, J. (1980b). Investment in human capital and social self-protection under'uncertainty. International Economic Review 21: 547-558.

Nitzan, S., and Paroush, J. (1982). Optimal decision rules in uncertain dichotomous choice situations. International Economic Review 23 (2) (June): 289-297.

Nitzan, S., and Paroush, J. (1984). Are qualified majority rules special? Public Choice 42 (3): 257-272.

Owen, G. (1975). Evaluation of a presidential election game. American Political Science Review 49: $947-953$.

Owen, G. (1983). 'Fair' indirect majority rules. Unpublished manuscript.

Owen, G., Grofman, B., and Feld, S. (1981). A theorem on the optimal distribution of competence within a group. Unpublished manuscript.

Penrod, S., and Hastie, R. (1979). Models of jury decision-making: A critical review. Psychological Bulletin 86: 462-492.

Philips, L.D. (1973). Bayesian statistics for social scientists. New York: Orwell.

Pierce, W. (1961). Improving reliability of digital systems by redundancy and adaptation. Ph.D. Thesis in Electrical Engineering, Stanford University.

Pinkham, R.S., and Urken, A.B. (1981). Competence and the choice of a voting system. Unpublished manuscript.

Plott, C. (1976). Axiomatic social choice theory: An overview and interpretation. American Journal of Political Science 20 (August).

Poisson, S.D. (1837). Recherches sur la probabilité des jugement en matière criminai et en matière civile: Précédées des règles générales du calcul des probabilités. Paris: Bachelier, Imprimateur Libraire.

Rae, D.W. (1969). Decision-rules and individual values in constitution choice. American Political Science Review 63 (March): 40-56.

Riker, W.H., and Shapley, L.S. (1968). Weighted voting: A mathematical analysis for instrumental judgment. In J.R. Pennock and J.W. Chapman (Eds.), Representation. New York: Atherton Press.

Roberts, B. (1973). Extension of optimality criteria-Axiomatic approach to institutional choice. Journal of Political Economy 81 (2): 386-400.

Sattler, H. (1966). Effect of group variability on pooled group decisions. Psychological Reports 18 (3): 676-678.

Schofield, N. (1971). Ethical decision rules for uncertain voters. British Journal of Political Science 2: 193-207.

Schofield, N. (1972). Is majority rule special? In R. Niemi and H. Weisberg (Eds.), Probability Models of Collective Decision-Making. Columbus, Ohio: Merrill.

Schotter, A. (1979). Voting weights as power proxies. In S. Brams, G. Schwödiauer and A. Schotter (Eds.), Applied game theory. Vienna: Physica-Verlag.

Shapley, L.S. (1962). Simple games: An outline of the descriptive theory. Behavioral Science 7: $59-66$.

Shapley, L.S., and Shubik, M. (1954). A method for evaluating the distribution of power in a committee system. American Political Science Review 48: 787-792.

Straffin, P.D. (1978). Probability models for power indices. In P.C. Ordeshook (Ed.), Game Theory and Political Science, 477-510. New York: New York University Press.

Taylor, M. (1969). Proof of a theorem on majority rule. Behavioral Science 14 (May): 228-231. Thom, G. (1979). Bringing the left back home. New Haven: Yale University Press.

Walbert, T.D. (1971). Note: Effect of jury size on probability of conviction - An evaluation of Williams v. Florida. Case Western Reserve Law Review 22: 529-555.

Young, H.P. (1974). An axiomatization of the Borda Rule. Journal of Economic Theory 9: $43-52$. 